\title{
DE LO MEDIEVAL Y LO RENACENTISTA EN LAS LETRAS HISPANOAMERICANAS DEL SIGLO XVI (*)
}

Antonio Antelo Iglesias

$U N E D$

Aunque no suficientemente investigado en orden a ciertos géneros y autores, el panorama literario de la América hispánica virreinal es bastante familiar a todos los estudiosos como para insistir acerca de sus figuras o creaciones representativas. Me limitaré, por tanto, a aducir una serie de textos y anotaciones sobre la coexistencia, durante el siglo XVI americano, de algunos rasgos medievales y renacentistas en la vida literaria'.

Los escritores de Indias no pueden ser valorados ni entendidos cabalmente si no es analizando los factores histórico-culturales de la Conquista y la Colonización, que determinaron un real mestizaje étnico, sociológico y

* Agradezco a los Profesores Miguel Angel Pérez Priego y Antonio Lorente Medina sus amables observaciones criticas y bibliográficas.

' La historiografia eclesiástica, el teatro misionario y la literatura didáctica quedan fuera del cuadro esbozado. Advertiré también que el marco cronológico puede rebasar el siglo XVI: me atengo a la división propuesta por $\mathrm{E}$. Anderson Imbert, Historia de la literatura hispanoamericana. 2." ed. corregida y aumentada, vol. I, México, Fondo de Cultura Económica, 1970, págs. 17-84 (Colec. «Breviarios», N. ${ }^{\circ}$ 89); es decir, el primer Renacimiento (1492-1556, nacidos de 1451 a 1530) y el segundo Renacimiento y Contrarreforma (1556-1598), nacidos de 1530 a 1570 ), pero con la inclusión, ocasional, de autores y géneros correspondientes a la tercera fase, del Renacimiento al Barroco (1598-1701, nacidos de 1570 a 1675). Tomo en consideración asimismo el Esquema generacional de las letras hispanoamericanas (Ensayo de un método), por J.J. Arrom, Bogotá, Instituto Caro y Cuervo, 1963. Vuelvo aquí sobre algunos de los temas abordados en diversos trabajos, como son, entre otros: Literatura y sociedad en la América española del siglo XVI. Notas para su estudio, "Thesaurus» (Bogotá), XXVII (1973), 279-330; El mito de la Edad de Oro en las letras hispanoamericanas del siglo XVI. "Thesaurus", XXX (1975), 81-112, y Perfil literario de Jiménez de Quesada, "Correo de los Andes" (Bogotá), 4142 (1987), 140-144. 
espiritual, ostẹsible en numerosos autores, como Agustín Yáñez ha sabido apuntar: "Ya en el solo estilo - advierte-, y desde sus principios, la literatura iberoamericana es mestiza, cuando es auténtica, condicionada, como está, por la realidad específica del Nuevo Mundo y por el proceso vital correspondiente; lo que se acentúa en medida del desarrollo histórico y del característico afán americano de independencia en todos los órdenes» ${ }^{2}$. Se refiere a Hernán Cortés, Bernal Díaz del Castillo, fray Bartolomé de las Casas, Alvar Núñez Cabeza de Vaca, Pedro Cieza de León, Juan de Betanzos y Martín del Barco Centenera, entre los que ofrecen ya tales notas, al menos virtualmente, y agrega: “Con el destino de Iberoamérica, estos documentos fundan el destino de la literatura iberoamericana. Compárese: si suena en ellos el prodigioso metal del español -llegado a máxima riqueza-, ni en el contenido, ni en la forma, pueden incorporarse a la literatura castiza de la Península. Se les ha insertado un espíritu ajeno: aun la lengua está contaminada no sólo con vocablos y giros antípodas, no sólo con asuntos de fábula; más todavía, normas inconcebibles de pensar y sentir los condicionan. Esta última es la fuerza decisiva del mestizaje como estilo literario, y la creadora de una nueva literaturas ${ }^{3}$.

Hay que tener en cuenta asimismo la notable contribución indígena: un don Fernando de Alva Ixtlilxóchitl, un Titu Cussi Yupanqui, o un Felipe Huamán Poma de Ayala.

Ese "pequeño género humano» del que hablaba ya el Libertador Simón Bolívar ${ }^{4}$, ese "hombre nuevo" sobre el cual nos han brindado sugestivas páginas Vasconcelos, Ortega y Gasset, Euclides da Cunha y otros ensayistas $^{4 b i s}$, los ha puesto a su vez de relieve Pedro Henríquez Ureña, al ocuparse de aquella sociedad naciente: «Toda esta literatura — afirma- pertenece a la América hispana mucho más que a España y Portugal $\aleph^{5}$. El encuentro de culturas es patente en el bilingüismo que distingue a tantos autores: "Y algunos de los que escribieron en una sola lengua - reitera el ilustre historiador y crítico dominicano- parecen haber pensado en dos: Santa Cruz Pachacuti (que escribió pobremente en español), Blas Valera,

2 A. Yáñez, El contenido social de la literatura iberoamericana, «Jornadas» (México), 14 (s.d.), pág. 20.

${ }^{3}$ A. Yáñez, art' cit., págs. 20-21.

4 «Nosotros somos - escribía en su carta de Jamaica, 1815- un pequeño género humano; poseemos un mundo aparte, cercado por dilatados mares, nuevo en casi todas las artes y ciencias, aunque en cierto modo viejo en los usos de la sociedad civil»: v. Simón Bolívar. Escritos políticos, 4." ed., Bogotá, El Áncora Editores, 1983, pág. 25.

4 bis J. Vasconcelos, La raza cósmica (1925) e Indología (1926); E. Da Cunha, Os sertões (1902); J. Ortega y Gasset, Meditación del pueblo joven (1939), etc.

P. Henriquez Ureña, Las corrientes literarias en la América Hispánica, México, Fondo de Cultura Económica, 1954, págs. 54 y 219-220, más la n. 36. 
Alvarado Tezozómoc, Alba Ixtlilxóchitl, y el primero de nuestros clásicos, el Inca Garcilaso»".

Ahora bien, reconociendo la trascendencia de tal mestizaje para una aproximación a la literatura virreinal del siglo XVI, la finalidad que me guía es tan sólo, insisto, la de señalar temas, géneros e ideales que el Viejo Mundo legó al Nuevo mediante el vehículo de la lengua castellana; fenómeno éste de transculturación en el cual se manifiestan las ambigüedades y contradicciones del Renacimiento como época incierta. Por lo demás, no faltan los autores indios o mestizos imbuidos de las mismas preocupaciones y tendencias que muestran los peninsulares o los criollos en ciernes, tanto en virtud de la translatio imperii como de la translatio studii.

\section{TRADICIONALIDAD Y CLASICISMO: LÍRICA Y ÉPICA}

Si aspiramos a situar en una perspectiva justa las facetas medievales y renacentistas que descubrimos en la producción literaria de Indias durante el siglo XVI, no podremos considerarla independientemente de la Metrópoli. Aunque se den a veces rasgos muy originales - como, por ejemplo y dentro de su rica variedad, en los cronistas-, es innegable que autores y público vivian de prestado. E. Anderson Imbert to ha subrayado al recordar la circulación, en América, de los géneros florecientes en la Península: «novelas caballerescas, pastoriles, picarescas, sentimentales; comedias; escritos erasmistas; historias, leyendas, alegorías, amenidades didácticas...»? La actitud era imitativa $\mathrm{y}$, por lo general, de tono menor los frutos cosechados.

La tradicionalidad poética se acusa en las Indias al igual que en la Península, no obstante los influjos de Italia y, a través de sus más laureados vates, de la Antigüedad clásica. «El humanismo de los españoles del siglo XVI - ha puntualizado certeramente F. López Estrada- no fue suficiente para asegurar el triunfo de un gusto literario dentro de una disciplina de orientación clásica»" La vigencia de temas y formas métricas propiamente medievales, corre parejas con la adopción fervorosa de los renacentistas o italianizantes: conservadores e innovadores no son exclusivistas. Junto a Garcilaso, Castillejo. Si el primero se adhiere al petrarquismo y acoge las

- P. Henriquez Ureña, ob. cit., pág. 59.

7 E. Anderson Imbert, ob. y vol. cits., pág. 57.

${ }^{8}$ F. López Estrada, Introducción a la literatura medieval y española, 3." ed. renovada, Madrid, Gredos, 1966, pág. 309 (v. también la 4." ed., 1979, págs. 547-553). Del mismo, es interesante el Perfil literario del Emperador Carlos, "Anales de la Universidad Hispalense», XXII (1962), 63-84. Add.: J. Scudieri Ruggieri, Cavalleria e cortesia nella vita e nella cultura di Spagna, Modena, 1980, págs. 322-334. 
consignas de Italia, otros representantes de esa escuela cortesana son, por su sensibilidad, epígonos de la lírica medieval, como piensa L. Rosales ${ }^{9}$; y si el segundo, vehemente defensor de la antigua versificación castellana - en particular, el octosilabo-, censura por boca de poetas anteriores las nuevas coplas que «por rodeo / van diciendo su intención», y que "corren con pies de plomo, / muy pesadas de caderas» ${ }^{10}$, es tan renacentista en el fondo como el que más; «de espíritu clásico y humanista - le conceptuó $\mathrm{M}$. Menéndez y Pelayo-: libre, audaz en la intención, viva, fresca y espontánea en su juvenil alegría» ${ }^{11}$.

Esta época ofrece aspectos y peculiaridades que, según F. de Onís, «coexisten naturalmente en el mismo medio, en los mismos espíritus, muy a menudo en las mismas obras... No se trata de una mezcla o yuxtaposición, como a veces ocurre en épocas de confusión y discordia, sino de manifestaciones diversas que tienen su origen en una misma actitud de espíritu» ${ }^{12}$. Así, el italianismo debe considerarse "uno de los varios elementos que constituyen el renacimiento literario de España, y entre ellos es el último en aparecer y el más débil en triunfar. Es, desde luego, el menos característico y hondo de la épocan ${ }^{13}$.

El cuadro que, por su parte, nos trazó R. Menéndez Pidal, basado en su teoría de los «frutos tardíos», ilustra bien la ambivalencia del período aquí evocado: «La Musa hispana en el coro apolíneo - concluía el gran maestro- aparece, ante todo, canéfora de esos frutos tardios, y entre las otras musas románicas se muestra voluntariosa, de juvenil e indócil espontaneidad ${ }^{14}$.

'L. Rosales, «La poesia cortesana», en Homenaje a Dámaso Alonso, vol. III, Madrid, Gredos, 1963, págs. 287-335.

${ }^{10} \mathrm{C}$. de Castillejo, Obras de amores. Obras de conversación y pasatiempo. Ed., prólogo y notas de J. Domínguez Bordona, 4." ed., Madrid, Espasa-Calpe, 1969, págs. 194-195 (Colec. «Clásicos Castellanos», 79).

"Insistiendo sobre esta valoración por Menéndez y Pelayo (Antologia de poetas líricos castellanos, $O C, \mathrm{X}$, Madrid, 1945), M. Arce de Vázquez dice: «La resistencia de Castillejo se deberá, más que a un pueril sentimiento reaccionario - ¿o patriótico?-, a que su poesía es menos intelectual que la de Garcilaso. Este es renacentista en su ideal de belleza; aquél lo es, sobre todo, en el ímpetu vital. El tradicionalismo de Castillejo se limita a la técnica; en el contenido, su poesía es gemela de la de Garcilason: v. Garcilaso de la Vega. Contribución al estudio de la lírica española del siglo XVI, Madrid, 1930 (Anejos de la «Revista de Filología Española», XII); cito por la nueva ed., Universidad de Puerto Rico, Rio Piedras, P.R., 1961, págs. 11-12. O.H. Green, por su parte, no cree que Castillejo difiera de sus predecesores y sucesores en orden al conflicto amor-razón: v. Spain and the Western Tradition. The Castilian Mind from "El Cid» to Calderón, vol. II, Madison, Univ. of Wisconsin Press, 1968, p. 201.

${ }_{12}$ F. de Onís, Ensayos sobre el sentido de la cultura española, Madrid, 1932; pasajes recogidos por A. del Río y M.J. Benardete, El concepto contemporáneo de España. Antología de ensayos (1895-1931), Buenos Aires, Losada, 1946, págs. 629-630.

${ }_{13}$ Ibídem.

14 R. Menéndez Pidal, "Caracteres primordiales de la literatura española», en Los españoles 
No olvidemos, además, cuán diferente de la nuestra, como lectores o críticos, fue la perspectiva literaria de los siglos áureos. A. Rodríguez Moñino ha llamado la atención, por ejemplo, sobre la lentitud con que se difundió la poesia lírica, manuscrita o impresa. Recordemos también que las prensas nos han transmitido los géneros y temas tradicionales, sin aparente solución de continuidad, en millares de pliegos sueltos ${ }^{15}$.

La América Hispana viviría esa coexistencia de lo medieval y lo renacentista - en poesía como en otras muchas expresiones literarias y culturales - desde el alba misma de su historia. Juan de Castellanos es, entre otros, un buen testigo de la lealtad a las formas y temática tradicionales. Cuando rememora sus charlas de sobremesa con el Mariscal Gonzalo Jiménez de Quesada - hombre del Renacimiento, pero también, como sostiene V. Frankl, exponente del manierismo y de la Contrarreforma, con fuertes resonancias medievales, $v$. $g r$. el agustinismo ${ }^{16}-$, dice el Beneficiado de Tunja:

Yél porfió conmigo muchas veces
ser los metros antiguos castellanos
los propios y adaptados a su lengua,
por ser hijos nacidos de su vientre,
y éstos, advenedizos, adoptivos
de diferente madre, y extranjera... ${ }^{17}$

Castellanos reconoce que el Fundador de Santa Fe de Bogotá y del Nuevo Reino de Granada no era «ayuno / del poético gusto y ejercicio»; así, pues, muy probablemente compuso algunas rimas de corte clásico, pero como su producción literaria se ha perdido casi totalmente, ignoramos la

en la Historia y en la Literatura. Dos ensayos. Buenos Aires, Espasa-Calpe Argentina, 1951, pág. 227.

is A. Rodríguez Moñino, Construcción critica y realidad histórica en la poesia española de los siglos XVI yXVII, Madrid, Castalia, ${ }^{2} 1968$; especialmente págs. 18-32 y 45-55. Cf. también: A. Deyermond. La literatura oral en la transición de la Edad Media al Renacimiento, "La Edad de Oro» (Madrid), VII (1988), 21-32.

16 V. Frankl, El "Antijovio" de Gonzalo Jiménez de Quesada y las concepciones de realidad $y$ verdad en la época de la Contrarreforma y del Manierismo, Madrid, Ediciones Cultura Hispánica, 1963. Vid. A. Antelo Iglesias, "Indice histórico español» (Barcelona), fasc. 40-41 (1964), N. ${ }^{\circ} 54683$.

17 J. de Castellanos, Historia del Nuevo Reino de Granada, ed. A. Paz y Mélia, 2 vols., Madrid, 1886; v. vol. I, canto XIII, págs. 366-367. 
cuantía, variedad y altura de los escarceos quesadinos. «Si los conocimientos de éste - díce J.M. Rivas Sacconi- no fueron meramente teóricos y se movilizaron hacia el poético ejercicio, el fundador de Santa Fe sería el primero entre los poetas latinos del parnaso nacional ${ }^{18}$. A través del Antijovio podemos rastrear su posición lingüística, literaria e ideológica, a todas luces conservadora ${ }^{19}$.

A su vez, Castellanos, familiarizado con los autores clásicos, no sólo hace gala de un virtuosismo poético-histórico al cantar, en romance, las gestas españolas de Indias, sino que se destaca por sus epitafios en latín, especialmente los dedicados a Jiménez de Quesada, Sebastián de Belalcázar y otros conquistadores. Esa práctica fue general en el siglo XVI: el túmulo imperial de México, en honor de Carlos V (1559), cuyas inscripciones revelan el decoro de las bonae litterae en la Nueva España, puede servir aquí de acabada y elegante muestra ${ }^{20}$.

Tunja se convirtió, gracias a Castellanos y su «academia», en centro de irradiación de la nueva manera poética, originaria de Italia, «en el punto de reunión ideal de todos los buenos y malos versificadores» neograna$\operatorname{dinos}^{21}$.

Respecto a México, fue probablemente Gutierre de Cetina quien introdujo, hacia 1546, el endecasílabo: «Su rastro —-según A. Reyes- puede haber sido la importación de la dulce lírica italiana, que aquí, como en la metrópoli, dialogará con la robusta musa de Herrera» ${ }^{22}$.

El primer nombre ilustre de la poesía hispanoamericana, Francisco de Terrazas (¿1525?-¿1600?), criollo, hijo de conquistador y elogiado por Cervantes en La Galatea, como «nuevo Apolo» entre los «ingenios soberanos»

18 J. M. Rivas Sacconi, El latin en Colombia. Bosquejo histórico del humanismo colombiano. Bogotá, Instituto Caro y Cuervo, 1949, pág. 8.

${ }_{19} C f$. la edición crítica de El Antijovio, por R. Torres Quintero y M. Ballesteros Gaibrois, Bogotá. Instituto Caro y Cuervo, 1952. Además de la excelente obra de V. Frankl, v.: R. Torres Quintero, El lenguaje de Jiménez de Quesada, "Studium» (Bogotá), I (1957), 197-209, y C. Valderrama Andrade, Jiménez de Quesada y el humanismo contrarreformista, Bogotá, Instituto Caro y Cuervo, 1965; tirada aparte de "Thesaurus", XX (1965).

${ }^{20}$ J. M. Rivas Sacconi, El latín en Colombia, págs. 25-31.

${ }^{21}$ J. M. Rivas, ob. cit., pág. 31. Aludiendo, entre otros, a Juan de Castellanos y los italianizantes, dice M. Menéndez y Pelayo: «Se ve que los humanistas del Nuevo Mundo no andaban rezagados, y que recibieron pronto las novedades literarias que por vía de Italia se habian comunicado a nuestros ingenios" (v. Historia de la poesia hispanoamericana, vol. I, Madrid, 1911, pág. 26). Respecto a la tradición clásica en Indias, ofrece un bosquejo útil T. B. Jones, The Classics in Colonial Hispanic America, "Transactions of the American Philological Association", LXX (1939), 37-45. Se añadirá, para la Nueva España, A. Méndez Plancarte, Los fundadores del humanismo mexicano, Bogotá, Instituto Caro y Cuervo, 1945.

${ }^{22}$ A. Reyes, «Letras de la Nueva España», en Obras completas, vol. XII, México, El Colegio de México, 1960, pág. 336. 
de América ${ }^{23}$, gozaba ya de merecida fama en su natal México, hacia 1577. Encarna la síntesis quinientista por sus composiciones en latín, español e italiano. A la sazón, «junto con el latín, que era el punto de partida de la enseñanza en las escuelas de las ciudades, se leía el italiano, que era adorno común para toda persona culta de habla española o portuguesa ${ }^{24}$. Los estudios críticos sobre Terrazas han permitido valorar su poesía en el marco de las letras novohispanas. Entre los sonetos más bellos del siglo XVI, figura uno en el que es patente la imitación de Camões:

\author{
Dejad las hebras de oro ensortijado \\ que el ánima me tienen enlazada, \\ y volved a la nieve no pisada \\ lo blanco de esas rosas matizado.
}

Dejad las perlas y el coral preciado

de que esa boca está tan adornada,

$y$ al cielo - de quien sois tan envidiada-

volved los soles que le habéis robado.

La gracia y discreción que muestra ha sido

del gran saber del celestial maestro, volvédselo a la angélica natura;

y todo aquesto asi restituido, veréis que lo que os queda es propio vuestro: ser áspera, cruël, ingrata y dura ${ }^{25}$.

${ }^{23}$ Cf. el «Canto de Caliope» en La Galatea, ed. de R. Schevill y A. Bonilla y San Martín, Madrid, 1914, vol. II, pág. 226, así como el notable Estudio crítico de "La Galatea", por F. López Estrada, La Laguna, 1948.

${ }^{24}$ P. Henríquez Ureña, Historia de la cultura en la América Hispánica, 5."ed., México, Fondo de Cultura Económica, 1961, pág. 39 (Colec. Popular, 5).

${ }_{25}$ Vid. A. Méndez. Plancarte, Poetas novohispanos. Primer siglo (1521-1621). Estudio, selección y notas de..., 2." ed., México, Universidad Nacional Autónoma de México, 1964, pág. 29 («Biblioteca del Estudiante Universitario», 33). Se consultará, aparte de M. Menéndez y Pelayo (Historia..., I, págs. 37-42) y J. García Icazbalceta (Francisco de Terrazas y otros poetas del siglo XVI, «Memorias de la Academia Mexicana», II, 1884, pág. 4), a A. Castro Leal para la edición, prólogo y notas de las Poesias de Terrazas, México, 1941. Según J. Caillet-Bois, «Terrazas, poeta latino, toscano y castellano, está más cerca de Cetina que de Herrera. Hay siempre en él una insistencia de la imagen concreta y una falta evidente de destreza para la abstracción, muy alejada de la concepción intelectualizada de Herrera, que vive un mundo poético empobrecido en imágenes externas y maneja una lengua voluntariamente limitadas: v. «Revista de Filología Hispánica», V (1943), pág. 77. En cuanto al modelo portugués del soneto, parece admitirse el de Camões, "Tornai essa brancura à alva açucena...", si bien $\mathrm{A}$. Salgado Júnior mantiene algunas reservas sobre la autoría de éste: v. L. de Camões, Obra completa. Organização, introdução, comentários e anotações do Prof..., Rio de Janeiro, Aguilar, 1963, pág. 558 y n. de la pág. 866 al soneto N. ${ }^{\circ} 206$ (FS-1668). 
Los otros sonetos «al itálico modo» son, para A. Reyes, "de excelente escuela y tersa factura en general, pero algo monótonos, siempre en torno al asunto de la belleza y la crueldad de la amada, asunto con que Petrarca invadió a Europa. Terrazas no alcanza la limpidez platónica de Herrera, otro de sus maestross ${ }^{26}$.

También en la Nueva España sobresalió Antonio de Saavedra Guzmán (n. antes de 1570), perteneciente al círculo de Terrazas y que, como éste, cultivaría el género épico sin demasiado éxito. Su poema en octavas reales, El peregrino indiano (1599), contiene antilogías medievales para definir el amor:

\begin{abstract}
iOh hiel envuelta en miel emponzoñada, oh tósigo mortal, oh dulce muerte, oh mal de muerte, oh muerte regalada y dicha que en desdicha se convierte! ¡Oh vida de la vida desastrada, oh inquietud de la felice suerte, oh brasa envuelta en hielo, oh vario efecto, confusión del estado más perfecto? ${ }^{27}$
\end{abstract}

Abundan los ejemplos castellanos. Tal urdimbre de paradojas y antítesis, entre provenzal y petrarquista, la hallamos en Lope de Stúñiga:

Vida será mi muerte,
y muerte será vida...

Como, asimismo, en una esparsa o composición breve de tono epigramático, cuyo autor es Rodrigo de Cota:

${ }^{2 \hbar}$ A. Reyes, Letras de la Nueva España..., pág. 338.

27 Vid. A. Méndez Plancarte, Poetas novohispanos.... pág. 100.

28. Cancionero castellano del siglo XV, ed. por $\mathrm{R}$. Foulché-Delbosc, 2 vols., Madrid, BaillyBaillière, 1912 y 1915 (NBAAEE, 19 y 22); vol. II, pág. S92. Ultimamente, debe verse: N. Salvador Miguel, La poesia cancioneril: el "Cancionero de Estúñiga», Madrid, Alhambra, 1977. Otro de los poetas, Juan de Tavira, recurre a tales antitesis: "Cuydados, dad ya vagar, / que syn pena / un momento pueda estar / este mi triste pensar, / que condena/mi vivir, a qué viviendo / syn vivir, / de males que non syntiendo, / muera mi vida muriendo / syn morirn. $C f$. «Ven muerte tan escondida...», en el Cancionero General de H. del Castillo. 
Vista ciega, luz oscura, gloria triste, vida muerte, ventura de desventura, lloro alegre, risa incierta, hiel sabrosa, dulce agrura, paz y ira y saña presta es amor, con vestidura de gloria que pena cuesta... ${ }^{29}$

A su vez, Diego de San Pedro repite el motivo:

Esta es la triste morada del que muere porque muerte non le quiere,

en su Tractado de amores de Arnalte y Lucenda ${ }^{30}$; motivo que, según P. Le Gentil, acoge también el portugués João de Meneses, del Cancioneiro Geral de Garçia de Resende:

Porqu'es tormiento tan fiero

la vyda de my catyvo

que no byvo porque byvo

$y$ muero porque no muero ${ }^{31}$,

reiterado en la célebre glosa teresiana:

Vivo sin vivir en mi,

${ }^{29}$ Cancionero castellano del siglo XV, ed. Foulché-Delbosc, vol. Il, pág. 588.

${ }^{30}$ D. de San Pedro, Obras. Ed., prólogo y notas de S. Gili Gaya, 3." ed., Madrid, EspasaCalpe, 1967 (Colec. «Clásicos Castellanos», 133), págs. 6, 11, 27, 32 y 96.

"P. Le Gentil, La poésie lyrique espagnole et portugaise à la fin du Moyen Âge. Les thèmes et les genres, vol. I, Rennes, Plihon, 1949; vol. II, Les formes, id., 1953. Para João de Meneses, v. vol. I, pág. 133. Cf. la ed. del Cancioneiro de Garçía de Resende por Gonçalves Guimarães. 4." ed., 5 vols., Coimbra, 1910-1917. 
y tan alta vida espero,

que muero porque no muero... ${ }^{32}$

Admirablemente, y en prosa, Fernando de Rojas hace decir a Celestina en qué consiste el mal de amores, esa enfermedad psicosomática denominada hereos: «Es un fuego escondido, una agradable llaga, un sabroso veneno, una dulce amargura, una delectable dolencia, un alegre tormento, una dulce y fiera herida, una blanda muerte ${ }^{33}$.

Otro poeta lírico que representa asimismo la coexistencia de lo medieval y lo renacentista, es Pedro de Trejo -cuya residencia en México se documenta entre 1558 y 1575 - con sus coplas de arte mayor y manriqueñas, sus innovaciones en sonetos y serventesios, así como sus alternancias de endecasilabos italianos y de gaita gallega. Por unos versos que a la Inquisición parecieron sospechosos, fue condenado a cuatro años de galeras y a que «perpetuamente no haga coplas»; «práctica - apostilla zumbonamente A. Reyes- que en todos los tiempos sería plausible si hubiera jueces más que humanos ${ }^{34}$.

En cuanto a la épica, sin duda el mayor logro es La Araucana, de Alonso de Ercilla y Zúñiga (1534-1594); pero téngase en cuenta que el primer poema narrativo de tema heroico - sobre la conquista del Perú, y no en octavas reales, como aquél, sino en coplas de arte mayor- se atribuye a Francisco de Xerez, hacia 1534, fiel a la tradición castellana ${ }^{35}$.

El propio Ercilla, que personifica el siglo XVI indiano en su vida y en su poema, que recibió una educación humanística y que pertenece al Renacimiento en la más amplia extensión del término, como autor épico se mantiene asimismo dentro de los cauces tradicionales de la literatura española. La Araucana, a juicio de G. Highet «el primer libro importante que se escribió en América» ${ }^{36}$, y absuelto por el cura en el escrutinio de la bi-

${ }^{32}$ Sta. Teresa de Jesús, Prosa escogida. Selección, estudio y notas por A. González Palencia. Zaragoza, Editorial Ebro, "1976, págs. 126-128. También la hace suya San Juan de la Cruz: v. Poesias completas y comentarios en prosa a los poemas mayores. Nota preliminar y ed. de las poesias por D. Alonso. 2." ed. Madrid, Aguilar, 1963, págs. 53-56 (Colec. Crisol, N. 171 bis).

La Celestina, Aucto X; v. Tragicomedia de Calixto y Melibea. Libro también llamado "La Celestina". Ed. crítica por M. Criado de Val y G.D. Trotter, 3." ed. corregida. Madrid, CSIC, 1970, pág. 189. Add. O.H. Green (v. n. 11), vol. 1, pág. 114.

${ }_{34}$ A. Reyes, Letras de la Nueva España, pág. 338.

${ }_{35} \mathrm{R}$. de la Fuente Benavides, Autores del primer siglo de la literatura peruana, "Boletín bibliográfico», XII (1939), 268-332 y XIII (1940), 81-133.

${ }_{36} \mathrm{G}$. Highet, La tradición clásica. Influencias griegas y romanas en la literatura occidental, trad. españ., vol. I, México, Fondo de Cultura Económica, 1954, págs. 229-230. 
blioteca de Don Quijote - junto con La Austríada, de Juan Rufo, y El Monserrate, de Cristóbal de Viruěs-, como una "de las más ricas prendas de poesia que tiene España» ${ }^{37}$, ostenta un marcado sello clásico: son evidentes las afinidades y los préstamos de La Araucana respecto a La Farsalia, de Lucano, y al epos antiguo ${ }^{38}$. Ahora bien, Ercilla trata de ofrecer al mismo tiempo una "historia verdadera»; tanto, que en algunos pasajes se torna prosaico a fuer de exacto, como en esta minuciosa estrofa:

\author{
Heme, señor, de muchos informado, \\ porque con más autoridad se cuente; \\ a veinte e tres de abril, que hoy es mediado, \\ hará cuatro años, cierta y justamente, \\ que el caso milagroso aqui contado \\ aconteció, un ejército presente, \\ el año de quinientos y cincuenta, \\ y cuatro sobre mil por cierta cuenta... ${ }^{39}$
}

Se aparta, así, de las teorías estéticas del Renacimiento y enlaza con el verismo épico castellano: su poesía, en opinión de R. Menéndez Pidal, constituye un buen ejemplo de esa constante hispana de sentir poética la historia (Lucano, Prudencio, el Cantar de Mio Cid...); «es también poesía historial, sin más que escasos episodios en que intervienen maravillas de creencia popular, magias y sortilegios como el indio mago Fitón y su cueva, imitación de Lucano, o prodigios cristianos, como la aparición de la Virgen $\rangle^{40}$.

Afirma Ercilla haber compuesto su poema «en la misma guerra y en los mismos pasos y sitios, escribiendo muchas veces en cuero por falta de papel

37 Quijote, Primera Parte, cap. VI.

${ }^{38} \mathrm{G}$. Bellini se pronuncia, acerca de la formación literaria de Ercilla y frente a Menéndez y Pelayo, que subrayaba el modelo virgiliano, precisando que "en La Araucana se pone de relieve cumplidamente - en los detalles particulares, ya que no en la esencia - el conocimiento de la épica italiana, sobre todo de Ariosto"; pero, "sea como fuere -añade-, no hay duda de que tanto Virgilio como la Biblia le resultaban familiares a Ercilla»: Historia de la literatura hispanoamericana, Madrid, Castalia, 1986, págs. 116-117. Cf., sin embargo, el juicio crítico del ilustre erudito chileno J.T. Medina, Vida de Ercilla, México, 1948, y su edición de La Araucana ( 5 vols., Santiago de Chile, 1910-1918). Vid. últimamente la de M. A. Morínigo e I. Lerner, 2 vols., Madrid, 1979. Son de interés asimismo las consideraciones de B. Pastor, Discurso narrativo de la Conquista de América, La Habana, Casa de las Américas, 1983, págs. 341-373.

${ }^{39}$ Araucana, canto IX, estrofa 18. 205 y ss.

40 R. Menéndez Pidal. «Caracteres primordiales de la literatura española» (cf. n. 14), págs. 
y en pedazos de cartas, algunos tan pequeños que apenas cabian seis ver$\operatorname{sos}\rangle^{41}$.

«El poeta - dice L.A. Sánchez- se deja arrastrar por el prurito realista, de historiador puntual y enumerativo. Se advierte que las estrofas son como notas rimadas de un corresponsal de guerra que combate y canta. Esa puntualidad mata al barroco, reitera al realista, define al español: sueño de la carne, espuma de la arcilla» ${ }^{42}$.

Merced a los nexos y "afinidades electivas» que unen a los poetas de Indias, en pleno siglo XVI, con las tradiciones peninsulares, el verismo castellano aflora pujante en América: un Diego de Aguirre y Córdoba, o un Martín del Barco Centenera, serán quienes pasen, entre otros, al primer plano - hechas las salvedades correspondientes en orden a sus méritos respectivos-; mientras que los "verosimilistas" (Bernardo de Balbuena, por ejemplo) quedarán relegados a un segundo lugar.

\section{El PERENNE ROMANCERO}

Desde que, a comienzos del siglo, Ramón Menéndez Pidal rastreó y pudo cosechar bastantes romances tradicionales de América, se ha progresado notoriamente en su investigación. "Bien podemos decir con seguridad -escribiria el docto filólogo al cabo de los años-que un copioso romancero pasó a América en la memoria de aquellos que tripulaban las naves descubridoras y en el recuerdo de cuantos, después, allá fueron ${ }^{43}$.

Ciertamente, la presencia de este acervo épico-lírico, de los «Romanceros» o colecciones de romances, se confirma - según I.A. Leonard- «en casi todas las listas de libros» y, muy a menudo, representan ellos solos la literatura de ficción entre los habituales títulos a nombre de algún destinatario eclesiástico ${ }^{44}$.

Gracias a los trabajos que en la América Hispana y en los Estados Uni-

${ }^{41}$ Araucana, Prólogo (v. ed. J.T. Medina).

${ }^{42}$ L.A. Sánchez, Escritores representativos de América, 2." ed., vol. I, Madrid, Gredos, 1963, pág. 14.

${ }^{43}$ R. Menéndez Pidal, Los romances de América y otros estudios, 7." ed., Madrid, EspasaCalpe, 1972 (Colec. Austral, 55) y también su Romancero hispánico. Teoria e historia, vol. II, Madrid, Espasa-Calpe, 1953, pág. 226. El capítulo XVI está dedicado a la «Difusión territorial del Romancero. Siglos xv-xvil». Vid., últimamente: M." C. Garcia de Enterría, Romancero. ¿cantado-recitado-leido?, «La Edad de Oro», VII (1988), 89-104.

${ }^{4}$ I. A. Leonard, Books of the Brave: Being an Account of Books and of Men in the Spanish Conquest and Settlement of the Sixteenth Century New World. New York, Gordian Press, 1964, pág. 120 (Reimpresión de esta obra, ya clásica, publicada en 1949). Trad. espñ.: Los libros del conquistador, México, Fondo de Cultura Económica, 1953, págs. 110-111. 
dos se han publicado sobre la materia, nuestro actual conocimiento del romancero en América se ha enriquecido y afinado considerablemente ${ }^{45}$.

Cuando Hernán Cortés, en 1519, reconocía las costas de México, sus hombres tuvieron una gran ocasión: escuchar cómo él intercambió algunos versos con cierto caballero. Dice así Bernal Díaz del Castillo, que es quien narra el hecho: [Desde Tabasco] «fuimos la vía de San Juan de Ulúa...; e yendo navegando con buen tiempo, decíamos a Cortés los que sabiamos aquella derrota: 'Señor, allí queda... el gran río de Guazagualco... y las muy altas Sierras Nevadas..., y la Isla Verde... y la de Sacrificios'; y luego en buena hora llegamos a San Juan de Ulúa, Jueves de la Cena, después de medio día. Y acuérdome que se llegó un caballero que se decía Alonso Hernández Puertocarrero, e dijo a Cortés: 'Paréceme, señor, que os han venido diciendo estos caballeros...

Cata Francia, Montesinos, /cata Paris, la ciudad, cata las aguas del Duero / do van a dar en la mar.

Yo digo que miréis las tierras ricas, y sabeos gobernar luego'. Cortés, entendiendo perfectamente el sentido de esas palabras, contestó:

!Dénos Dios ventura en armas / como al paladín Roldán: que en lo demás, teniendo a vuesa merced y a otros caballeros por señores, bien me sabré entender'.., $)^{46}$

${ }^{45}$ Entre las aportaciones más estimables, v.: L. R. de Jijena Sánchez, Poesia popular y tradicional americana, Buenos Aires, 1952. L. Santullano, La poesia del pueblo. Romances y canciones de España y América, Buenos Aires, 1955. W. A. Reynolds, Romancero de Hernán Cortés. Estudio y textos de los siglos xvI y xvI, Madrid, 1967. S. Toscano, Los romances viejos en México, en el siglo XVI, y un romance anónimo a Cortés, "Filosofia y Letras» (México), XIV (1947), 127-132 (Se trata del «Romance del Marqués del Valle», protestando por las medidas de Felipe II contra los descendientes de los conquistadores). A. M. Espinosa, Romancero de Nuevo México, Madrid, 1953 (Anejos de la "Revista de Filologia Española», 58) y, del mismo, "Los romances tradicionales en California", en Homenaje ofrecido a $R$. Menéndez Pidal, vol. I, Madrid, 1925, págs. 293-313. C. Poncet y Cárdenas, El romance en Cuba, La Habana, 1972. 'Romances de Puerto Rico', collected by J.A. Mason, and edited by A. M. Espinosa, "Revue Hispanique», XLIII (1918), 309-364. E. Romero, El romance tradicional en el Perú, México, 1952. R. Barros y M. Dannemann, El romancero chileno, Santiago de Chile, 1970. Add.: M.E. Simmons, A Bibliography of the 'Romance' and Related Forms in Spanish America, Bloomington, Ind., 1963.

${ }^{4}$ B. Diaz del Castillo, Historia verdadera de la conquista de la Nueva España. Introducción y notas por J. Ramirez Cabañas. 3 vols., México, 1944; cap. XXXVI. Cf. R. Menéndez Pidal, Romancero hispánico (cit. en la n. 43), vol. II, pág. 226 y notas. 
En otra jornada de la expedición, cuando a la «Noche Triste» siguió el alba de aquel sombrio $1 .^{\circ}$ de julio de 1520 , y Cortés miraba desde el templo de Tacuba la ciudad abandonada, el Bachiller Alonso Pérez, según Bernal Díaz (cap. CXLV), así le confortó: "Señor Capitán: no esté vuesa merced tan triste, que en las guerras estas cosas suelen acaescer, y no se dirá por vuesa merced:

Mira Nero de Tarpeya / a Roma cómo se ardía...»

Bernal inserta el «cantar o romance»:

En Tacuba está Cortés / con su escuadrón esforzado, triste estaba y muy penoso, / triste y con gran cuidado, / una mano en la mejilla / y la otra en el costado... $\rangle^{47}$

Limitándonos a Méjico, donde el romance se ha conservado hasta hoy como forma de expresión poética -dando origen a otra tan característica, tan nacional, como el corrido-, son de notar entre los más populares los de "La bella malmaridada», "El Infante Arnaldos", "La esposa infiel», «Delgadina», «Fontefrida», "La misa de amor», «El cerco de Zamora», "Bernardo del Carpio», "Roncesvalles» y otros muchos, entre ellos el de «La amiga de Bernal Francés»:

Sola me estoy en mi cama

namorando mi cojin;

¿quién será ese caballero

que a mi puerta dice: "Abrid"?

- Soy Bernal Francés, señora,

el que te suele servir...

Este bello romance - cuyo protagonista, capitán en la guerra de Granada, ha sido objeto de un exhaustivo estudio por parte de J.B. AvalleArce- se canta en la actualidad desde Andalucía a Santander, y entre los

${ }^{47}$ W. H. Prescott, History of the Conquest of Mexico. With a Preliminary View of the Ancient Mexican Civilization, and the Life of the Conqueror Hernando Cortés. Vol. II, Philadelphia, D. McKay ( $s . d$.), sobre la "Noche Triste» (págs. 305-320) y III, sobre Tacuba (Tlacopán, págs. 75-78, y el romance que recoge Bernal, Historia verdadera..., cap. CXLV). Vid. n. 43, R. Menéndez Pidal, Romancero hispánico..., vol. II, págs. 226-229. 
sefardíes de Oriente, así como en Chile. Con él se mantiene viva la tradición de otros muy antiguos, incluso en Nuevo México y Colorado ${ }^{48}$.

También el Perú, agitadísimo por la guerra civil entre pizarristas y almagristas, fue escenario de la recitación, en pleno combate o en las marchas forzadas, de romances viejos o surgidos al ritmo de la conquista. Diego de Almagro se salvó de una emboscada y, por tanto, de una muerte segura al oír cómo un soldado cantaba y recantaba, para que huyese:

Tiempo es, el caballero, tiempo es de andar de aquí. que me crece la barriga y se me achica el vestir... ${ }^{49}$

Otro personaje que figura en los romances es el «tirano» Lope de Aguirre, sublevado hacia 1560 contra Felipe II.

Cultivó asimismo el romance, con intención satírica, el pintoresco e ingenioso Mateo Rosas de Oquendo, cuya vida aventurera (1159?-c.1621), ágil producción poética y relieve sociocultural ha estudiado Alfonso Reyes ${ }^{\text {so }}$. Su graciosa invectiva contra los pujos aristocratizantes de los españoles llegados al Perú - siendo, como eran, de modesta extracción social, en su mayoría-, reviste esa forma métrica:

\author{
¿Qué de Pero Sánchez dones! \\ ¡Qué de dones Pero Sánchez! \\ ¡Qué de Hurtados y Pachecos! \\ ¿Qué de Enriques y Guzmanes! \\ ¿Qué de Mendozas y Leivas! \\ ¿Qué de Laras, qué de Zerdas,
}

${ }^{48}$ Sobre este romance, v. J. B. Avalle-Arce, Bernal Francés y su romance, "Anuario de estudios medievales» (Barcelona), 3 (1966), 327-391.

${ }^{49}$ W. H. Prescott (Peru, vol. II, New York, P. Fenelon Collier and Son, 1900, pág. 82, n. 24) refiere asi el hecho: «It was said Gonzalo Pizarro lay in ambush with a strong force in the neighborhood to intercept the marshal, and that the latter was warned of his danger by an honorable cavalier of the opposite party, who repeated a distich of an old ballad: 'Tiempo es el caballero. / tiempo es de andar de aqui'..." Se basa en A. de Herrera, Hist. general, déc 6.", lib. 3, cap. 4. . Vid. también n. 43, R. Menéndez Pidal, Romancero hispánico..., vol. II, págs. 230-231.

so Vid. Letras de la Nueva España (cit. en la n. 22), pág. 342, y, sobre todo, Rosas de Oquendo en América, $O C$, vol. VI, México, 1957, págs. 25-53; más sus Capitulos de literatura española, México, 1939, págs. 21-71. 


\author{
Buitrones y Salazares! \\ Todos son hidalgos finos \\ de conocidos solares; \\ no viene acá Juan Muñoz, \\ Diego Xil, ni Pero Sánchez; \\ no vienen hombres humildes, \\ ni judios, ni oficiales, \\ sino todos caballeros \\ $y$ personas principales... ${ }^{51}$
}

Aunque la vena mordaz le define como poeta - sobre todo en el Perú-tiene, sin embargo, acentos de real compenetración afectiva con México: «él mismo - afirma A. Méndez Plancarte - se encariñó con esta 'Ciudad insigne', y dijo la 'alabanza de Yucatán', y proyectó suaves lirismos de amor y melancolía sobre nuestros paisajes de Guadalupe y de los volcanes" ${ }^{52}$. Son muy estimables sus romances «Indiano volcán famoso", "Estando ayer en la calle» y "Montañas de Guadalupe»"

Tal arraigo del romancero explica que hasta los indios nobles sintieran el orgullo de imitar a los españoles; como, por ejemplo, don Fernando de Alva Ixtlilxóchitl (1568?-1648?), versadísimo en la lengua náhuatl y en las tradiciones indígenas, pero, a la vez, tan identificado con la poesía castellana que acertó a componer un magnífico romance del rey Don Sancho:

\author{
A los muros de Zamora \\ herido está el rey Don Sancho, \\ que del castigo de Dios \\ no hay seguro rey humano... \\ Vióse sin cetro y corona, \\ sin su pulido regalo,
}

" Lo incluye A. Reyes, ob. cit., pág. 33. A. Méndez Plancarte, Poetas novohispanos (v. n. 25), expone certeramente: "Sus versos — con algunos de Quevedo, Cervantes o Góngora, en la 'Sátira de Oquendo' (manuscrito de la Biblioteca Nacional de Madrid, extractado por Paz y Mélia, y por Reyes)- detallan pintorescamente la vida indiana del xvı, dando voz, en la 'ya abierta pugna', ora a los 'españoles americanos' contra los venidos después (Todos son hidalgos finos / de conocidos solares...; ¡Como si no se supiera / que allá rabiaban de hambre!...), ora al campo contrario, como en la 'Sátira que hizo un galán a una dama criolla que alababa mucho a México', donde burlescamente acopia nahuatlismos e ironiza a nuestro 'reino loco' de Nueva España» (págs. XLI-XLII).

${ }_{22}$ A. Méndez Plancarte, ob. cit., pág. XLII.

s3. Méndez Plancarte, ob. cit., págs. 137-144. 
y conocio que los reyes

eran estatuas de barro... ${ }^{54}$

\section{FICCIONES CABALLERESCAS ${ }^{55}$}

Entre los incentivos de la imaginación que obraron poderosamente sobre los exploradores y conquistadores españoles, hállanse los libros de caballerías $^{56}$. Las Leyes de Indias prohibieron su lectura ${ }^{57}$, muy criticada, además, por los moralistas y humanistas; pero su demanda fue tal, que llegaban a la persona misma de Carlos $\mathrm{V}$, egregio devoto del género ( $L e$ chevalier déliberé, del borgoñón Olivier de la Marche, entre otros ejemplos). La propia vida del César ilustra dicha afición literaria, pues el Emperador constituye el más acabado testimonio de idealismo cristiano-medieval, fruto tardío y, a la vez, encarnación de quijotescos reveses tras constantes vaivenes políticos y empresas militares de varia fortuna. Su espléndido retrato por Tiziano, en el campo de Mühlberg, irradia coraje, pero también melancolía; esa melancolía que el grabado famoso de Durero ha hecho clásica y que

${ }^{54}$ Figura en la selección de A. Méndez Plancarte, ob. cit., págs. 175-177 y 179-180.

ss Sobre la prosa de ficción, v., además de I. A. Leonard (n. 44), R. Chang-Rodriguez, Prosa hispanoamericana virreinal, Barcelona, Borrás, 1978, y C. Goić, "Novela hispanoamericana colonial», en: Historia de la literatura hispanoamericana, vol. I, Epoca colonial, Madrid, Cátedra, 1982. págs. 375-382. Sin embargo, son importantes aún P. Henriquez Ureña, «Apuntaciones sobre la novela en América", en Obra critica de Pedro Henríquez Ureña, México, 1960, págs. 618-626, y A. Torres Ríoseco, La novela en la América Hispana, Berkeley-Los Angeles, University of California Press, 1939, págs. 159-256 (especialmente, págs. 172-181).

st Para una información general, v.: H. Thomas, Spanish and Portuguese Romances of Chivalry. The Revival of the Romance of Chivalry in the Spanish Peninsula and its Extension and Influence Abroad. Cambridge, Eng., 1920. Hay trad. españ.: Las novelas de caballerias españolas y portuguesas. Despertar de la novela caballeresca en la Peninsula Ibérica y expansión $e$ influencia en el extranjero. Madrid, CSIC, 1952. Concretamente en relación con América, se destacan: A. Cioranescu, «La Conquista de América y la novela de caballerias», en Estudios de literatura española y comparada, La Laguna, Universidad de..., 1954, págs. 31-46. J. Fraser, America and the Patterns of Chivalry, Cambridge, Eng., 1982. S. Gilman, Bernal Diaz del Castillo and "Amadis de Gaula", en Studia philologica. Homenaje a Dámaso Alonso, vol. II, Madrid, Gredos, 1961, págs. 99-114. I. A. Leonard, Romances of Chivalry in the Spanish Indies. With some 'Registros' of Shipments of Books to the Spanish Colonies, Berkeley-Los Angeles, University of California Press, 1933. I. Rodríguez Prampolini, Amadises de América. La hazaña de Indias como empresa caballeresca. México, 1948. A. Sánchez, Los libros de caballerías en la Conquista de América, "Anales cervantinos» (Madrid), VII (1958), 237-259. R. Schevill, La novela histórica, las crónicas de Indias y los libros de caballerias, "Revista de las Indias» (Bo-

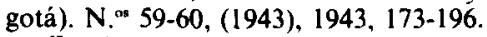

${ }^{57}$ Cf. la Recopilación de las Leyes de los Reynos de las Indias, 3 vols., Madrid, Consejo de la Hispanidad, 1943; Libro I, Título XXIV, Leyes 1."-15.". Vid. también M. J. de Ayala, Notas a la Recopilación de Indias. Transcripción de J. Manzano. 2 vols., Madrid, 1945-1946. 
pudiera ser,'como en el lienzo del pintor veneciano, expresión de la dualidad renacentista personificada en el arquetipo caballeresco ${ }^{58}$. Recordemos igualmente su discurso de abdicación en Bruselas (1556), muy afin por su espíritu a las últimas palabras del Hidalgo Manchego, perfectamente desengañadas y tan cuerdas... Cervantes admiraba al Emperador, mas no a su hijo, rey burócrata, frío y "Prudente», que decepcionó al César cuando éste, ya retirado para morir, en Yuste, supo que Felipe II no había estado al frente de sus tercios en la batalla de San Quintín (1557) ${ }^{59}$. Eran otros tiempos...

Si Carlos V tenía en gran estima los libros de caballerías, sus súbditos españoles los devoraban, provocando con ello las censuras de quienes atribuían a las "historias mentirosas» graves daños morales y estéticos. Así, Luis Vives, en la Instrucción de la mujer cristiana denuncia «estos libros vanos, como son, en España, Amadís, Florisando, Tirante, Tristán de Leonís y, a su lado, Celestina, madre de las maldades». Fray Antonio de Guevara, por su parte, sentía "compassion... de ver los días y las noches que consumen muchos en leer libros vanos: es a saber, a Amadís, a Primaleón, a Duarte, a Lucenda, a Calisto, con la doctrina de los quales ossaré dezir: que no passan tiempo, sino que pierden el tiempo: porque allí no deprenden cómo se han de apartar los vicios, sino qué primores ternán para ser más viciosos». Y Pedro Mexía clamaba por que fueran «desterrados de España: como cosa contagiosa y dañosa a la repúblican ${ }^{60}$. E. Glaser, en un excelente artículo, reunió más textos adversos - de autores eclesiásticos- a este tipo de historias $^{61}$. Bien sabemos, sin embargo, que hasta Santa Teresa, en su adolescencia, era devota de los libros de caballerías: "Yo comencé a quedarme en costumbre de leerlos — dice en el Libro de su vida-, y aquella

s8 Acerca del Imperio carolino y sus expresiones literarias en orden al "alma caballeresca» y al universalismo medieval, se tendrán presentes: J. Babelon, Carlos $V$ y la decadencia de la Caballería, «Cuadernos Hispanoamericanos» (Madrid), N.¹07-108 (nov.-dic. 1958), 296-302. O. H. Green (v. n. 11), vol. III, págs. 82-108. F. López Estrada (v. n. 8). J. A. Maravall, Carlos $V$ y el pensamiento politico del Renacimiento, Madrid, 1960. R. Menéndez Pidal, Idea imperial de Carlos V. 3." ed., Buenos Aires, Espasa-Calpe Argentina, ${ }^{3} 1946$, págs. 11-36 (Colec. Austral, 172). M. de Montoliú, El alma de España y sus reflejos en la literatura del Siglo de Oro, Barcelona, Editorial Cervantes, $s$. d., págs. 50-102 y 188-220. P. Rassow, El mundo politico de Carlos V. Trad. espñ. Introducción de R. Carande. Madrid, Afrodisio Aguado, 1945. Vid. una revisión de las interpretaciones más influyentes, hasta esa fecha, en el artículo de A. Antelo Iglesias, En torno al ideario politico de Carlos V: España, el Turco y la "universitas christiana», "Studium» (Bogotá), I (1957), 185-196. Se añadirá J. Scudieri Ruggieri (v. n. 8).

${ }^{59}$ Es interesante la semblanza del Emperador por J. Babelon (v. n. 58), sobre todo las págs. 299-302.

(*) J. L. Vives, Instrucción de la mujer cristiana, Buenos Aires, Espasa-Calpe Argentina, 1940, pág. 36 (Colec. Austral, 138). Fr. A. de Guevara, Relox de principes, Prólogo. Cit. por H. Thomas (v. n. 56), pág. 170. P. Mexía, Historia imperial y cesárea, Sevilla, Juan de León, 1545 .

${ }^{61}$ E. Glaser, Nuevos datos sobre la critica de los libros de caballerias en los siglos XVI y XVII, "Anuario de estudios medievales" (Barcelona), 3 (1966), 393-410. 
pequeña falta que en ella ví me comenzó a enfriar los deseos [de ir a tierras de moros para sufrir el martirio] y comenzar a faltar en lo demás; y parecíame no era malo, con gastar muchas horas de el día y de la noche, en tan vano ejercicio, aunque escondida de mi padre. Era tan estremo lo que esto me embevía, que si no tenía libro nuevo, no me parecía tener contento" ${ }^{62}$. Con su hermano Rodrigo llegó a componer, incluso, uno según el P. Francisco Pantaleón de Ribera, «con sus aventuras y ficciones, y salió tal que había harto que decir de él $\rangle^{63}$.

Las críticas se justificaban plenamente al sobrevenir la decadencia del género, por ser estos libros «en el estilo duros, en las hazañas increibles, en los amores lascivos, en las cortesías mal mirados... $\rangle^{64}$.

I. A. Leonard ha insistido, con abundante y nueva documentación, sobre la popularidad de los libros de caballerías en Indias: los conquistadores y pobladores, en general, apreciábanlos tanto, que es lícito preguntarse una vez más hasta qué punto influyeron dichas novelas como estímulo de la acción española en América. "Los escritos de ficción - reconoce el gran investigador - no son solamente los registros subjetivos de la experiencia humana, sino que a veces son los instigadores inconscientes de las reacciones del hombre ${ }^{65}$.

Efectivamente, los conquistadores entremezclaban sus propias fábulas y leyendas con las creencias y fantasias de los indios, «que, adulteradas en la traducción, llegaban a ellos en respuestas a sus preguntas mal entendidas» ${ }^{66}$. No cabe duda de que la literatura de ficción rivalizó con la devota, precediéndola, acaso, en la empresa indiana: «De haber nacido cincuenta años antes -dice A. Cioranescu-, quizá Don Quijote hubiera sido un conquistador $)^{67}$.

Los españoles redoblaron su energía en múltiples situaciones, excitándose con los libros de caballerías. M. Machado cantó en unos afortunados endecasílabos la gesta de aquellos «Amadises de América»:

Como creyeron, solos, lo increible sucedió: que los límites del sueño

\$2 Santa Teresa de Jesús, Obras. La vida. Camino de perfección. Las moradas. Edición, prólogo y notas por A. Comas. Barcelona, Editorial Vergara, 1961. Vid. la Vida, cap. II.

${ }_{63}$ F. P. de Ribera, Vida de Santa Teresa, Barcelona, 1908; lib. I, cap. V, pág. 90.

${ }^{4}$ Quijote, Primera Parte, cap. XLVII. pág. 9.

65 I. A. Leonard, Books of the Brave (v. n. 44), págs. VII-VIII; cito por la ed. espñ.,

io A. Leonard, Books of the Brave, pág. 315; ed. españ., pág. 254.

${ }^{67}$ A. Cioranescu, ob. cit. (v. n. 56), pág. 41. 
traspasaron, y el mar, y el imposible;

... y es, todo elogio a su valor, pequeño...

Capitanes de ensueño y de quimera, rompiendo para siempre el horizonte, persiguieron al sol en su carrera. ${ }^{68}$

Aunque los cronistas velen o condenen el ascendiente de esas obras (como, por ejemplo, Gonzalo Fernández de Oviedo, que en el prefacio al libro XVIII de su Historia natural y general de las Indias considera al Diablo patrono de tal literatura, pasando por alto que él mismo, en su juventud, publicó el Claribalte $)^{69}$, la huella de los libros de caballerías es patente. Así, en Bernal Díaz del Castillo, quien al avistar la capital azteca deja traslucir sus lecturas de "historias mentirosas»: "Y desque vimos - escribe- tantas ciudades y villas pobladas en el agua, y en tierra firme otras grandes poblazones, y aquella calzada tan derecha y por nivel cómo iba a México, nos quedamos admirados, y decíamos que parescía a las cosas de encantamiento que cuentan en el libro de Amadís, por las grandes torres y cúes y edificios que tenían dentro en el agua, y todos de calicanto; y aun algunos de nuestros soldados decían que si aquello que veían, si era entre sueños... ${ }^{70}$.

El punto más alto, en número, lo alcanzaron esos libros a mediados del siglo XVI, "frutos tardíos» de la tradicionalidad hispánica; el declive se presentó en la segunda mitad de la centuria, seguramente por los ataques de que eran objeto desde el púlpito y en los tratados de moral. El reinado de Carlos V marca, pues, su apogeo, con títulos nuevos año tras año e innumerables reimpresiones de los anteriores; pero, a partir de Felipe II y, sobre todo, bajo Felipe III, decaen a ojos vistas. Dos fechas pueden jalonar la trayectoria final: 1588 (desastre de la "Armada Invencible») y 1605 (primera parte del Quijote). Los cálculos de I. A. Leonard ponen de manifiesto el cambio producido en los gustos literarios, ya que entre 1508 y 1550 se imprimieron más de cincuenta novelas, y sólo nueve en las cuatro décadas siguientes $^{71}$. Durante el siglo de la Conquista se hicieron en España 316 ediciones de esos libros, de las cuales 109 — casi la tercera parte- salieron

${ }^{68}$ Citado por I. A. Leonard, Books of the Brave, pág. VI. Vid. M. y A. Machado, Obras completas, Madrid, Plenitud, 4." ed., 1957, pág. 170.

${ }_{69} V i d$. el Libro del muy esforzado caballero don Claribalte, por Gonzalo Fernández de Oviedo (1519). Sale nuevamente a la luz reproducido en facsimilar por acuerdo de la Real Academia Española. Madrid, 1956. Sobre esta obra, $c f$. D. Turner, Oviedo's "Claribalte», the First American Novel, "Romance Notes", V (1964), 66 sgs., y H. H. Orjuela, Origenes de la literatura colombiana: Gonzalo Fernández de Oviedo, "Thesaurus» (Bogotá), XL (1985), 241-292 (especialmente págs. 273-281).

${ }^{70}$ B. Díaz del Castillo, Historia verdadera... (v. n. 46), cap. LXXXVII.

"I. A. Leonard, Books of the Brave, pág. 18; ed. espĩ., pág. 30. 
de las prensas sevillanas, y 45 llevaban el pie de imprenta de Cromberger, quien ejerció un monopolio en México. No obstante, a finales de siglo deparaban todavía ganancias comerciales: en un documento del 22 de febrero de 1583, un tal Francisco de la Hoz, que viajaba a España, obligábase a traer de regreso a Lima, para el librero Jiménez del Río, unos dos mil volúmenes. «De mayor significación - observa Leonard - es el hecho de que más de la mitad de los libros pertenecía a la clase de obras que, según algunos historiadores, sólo llegaban a los lectores coloniales a través del contrabando. El hecho de que el librero de Lima manifestase públicamente su intención de comprar libros de caballerías, prohibidos por decretos reales, para revenderlos, es la mejor prueba de que a este respecto la ley era letra muerta; lo cual nos demuestra una vez más el peligro de basar la historia exclusivamente en la legislación ${ }^{72}$.

\section{Las amazonas y El Dorado}

Otro aliciente para los exploradores y conquistadores lo suministró la Antigüedad clásica, cuyos mitos, leyendas y tradiciones enlazaban con los del Oriente y la Europa medieval.

La existencia de países imaginarios con sociedades y organización, ya primitivas o exóticas, ya modelos de constitución perfecta (la Atlántida, las islas Afortunadas, las utopias de Euhémero y Yámbulo, etc.), fue también admitida por el hombre medieval, en casos tales como la isla de San Brandán, pletórica de gemas y luz solar; la Antilia, habitada por cristianos puros que vivian en régimen comunal muy próspero; y, desde luego, el Paraíso Terrenal, creencia universalmente compartida. Aunque muchos de esos lugares se situaban en Asia (cfr., por ejemplo, el De imagine mundi, de Honorio de Autun, a comienzos del siglo XII), el Poniente, el Mare Tenebrosum, atraían no menos el interés general, incitando así a la gran aventura oceánica: la génesis, la prehistoria del Descubrimiento se relaciona estrechamente con estas ensoñaciones ${ }^{73}$.

12 I. A. Leonard, Books of the Brave, pág. 220; ed. espĩ., 186.

73. Entre las exposiciones generales y monografias acerca de los mitos, leyendas y viajes que informan la génesis del Descubrimiento e influyen en la exploración del Nuevo Mundo, v.: J. Armstrong, The Paradise Myth. Londres, 1969. F. Bar, Les routes de l'autre monde. Descentes aux Enfers et voyages dans l'au-delà, Paris, Presses Universitaires de France, 1946, págs. 72 133. E. Benito Ruano, La leyenda de San Borondón, octava Isla Canaria, Valladolid, Universidad de ..., 1978. S. Buarque de Holanda, Visão do Paraiso. Os motivos edénicos no descobrimento e colonização do Brasil, Río de Janeiro, 1959, págs. 3-18 y 167-201. E. Déprez, Les grands voyages et les grandes découvertes jusqu'à la fin du XVIIIe siècle, «Bulletin du Comité 
Entre aquellos países - por lo general, islas- figura el reino de las Amazonas, cuya realidad se aceptaba desde Homero y se asociaba con los mitos de Heracles y Teseo. El distinguido etnólogo e historiador C. Alonso del Real ha dedicado un ameno, erudito y curioso libro al tema, en las más distantes latitudes y épocas, con algunas páginas esclarecedoras acerca de América ${ }^{74}$.

Ciertamente, los españoles se sintieron pronto movidos por relatos como los de El Dorado y las Amazonas, que trascendieron incluso a los contratos de exploración y conquista: aparecen en Colón, Pedro Mártir de Anghiera o de Angleria, Pigafetta, fray Gaspar de Carvajal -testimonio clásico-, y aun en extranjeros como Sir Walter Raleigh.

Entre 1493 y 1510 , Pedro Mártir difunde las insólitas novedades ultramarinas y habla de una isla habitada por mujeres solas: «En el primer viaje de Colón habían tenido los nuestros noticias de esta isla [Madanina]. Se ha creído que los caníbales se acercan a aquellas mujeres en ciertos tiempos del año, del mismo modo que los robustos tracios pasan a ver a las Amazonas de Lesbos, según refieren los antiguos, y que de igual manera ellas les envían los hijos destetados a sus padres, reteniendo consigo a las hembras. Cuentan que estas mujeres tienen grandes minas debajo de tierra, a las cuales huyen si alguno se acerca a ellas fuera del tiempo convenido; pero si se atreven a seguirlas por la violencia o con asechanzas y acercarse a ellas, se defienden con saetas, creyéndose que las disparan con ojo muy certero ${ }^{75}$. A continuación expone que el Almirante y los suyos tuvieron un encuentro con varones y hembras mandadas por una «a la cual, según se podía conjeturar..., le hacían cumplimiento como a reina». Los indios fueron derrotados, a pesar de su valerosa resistencia. Los españoles, «empujando con los remos la pequeña nave en que iban, volcaron la canoa [de los indios] con gran ímpetu, la cual, echada a pique, tanto los hombres como las mujeres, nadando, dirigían sus dardos a los nuestros con igual aliento y rapidez

International de Sciences Historiques", II, part. IVe, N. 9 (1930), 553-614. N. L. Goodrich, The Medieval Myths, New York, Mentor Books, 1961. A. Graf, Miti, leggende e superstizioni del Medio Evo. Turin, 1925. A. P. Newton, Travel and Travelers in the Middle Ages, Londres, 1949. L. Olschki, Storia letteraria delle scoperte geografiche. Florencia, 1937. H. R. Patch, El otro mundo en la literatura medieval. Seguido de un Apéndice: "La visión de trasmundo en las literaturas hispánicas», por M." R. Lida de Malkiel. Trad. espñ. México, Fondo de Cultura Económica, 1956. R. Thévenin, Les pays légendaires devant la science, $2^{c}$ éd., Paris, Presses Universitaires de France, 1948, págs. 40-91. Para las islas del Mare Tenebrosum, el estudio clásico sigue siendo la obra de d'Avezac, Les îles fantastiques de l'Océan Occidental au Moyen Âge, París, 1845.

${ }_{74}$ C. Alonso del Real, Realidad y leyenda de las Amazonas, Madrid, Espasa-Calpe, 1967 (Colec. Austral, 1396). Vid. también I. A. Leonard, Books of the Brave, caps. IV y V, para México y Suramérica.

${ }_{75}$ P. M. de Anghiera (o Angleria), Décadas del Nuevo Mundo. Trad. de J. Torres Asensio. Buenos Aires, 1944; v. Déc. I, lib. III, cap. VIII, págs. 17-18. 
que antes. Recogiéndose a cierta piedra cubierta de agua y peleando con valor, por fin fueron cogidos, muerto uno y con dos heridas el hijo de la reina» ${ }^{76}$.

Años después, el quinto libro de Amadis de Gaula, intitulado Las sergas de Esplandián, atribuido a Garci Ordóñez de Montalvo (Sevilla, 1510), incorporaría a este ciclo caballeresco la leyenda de las Amazonas y la reina Calafia: "Quiero agora que sepáis - dice - una cosa la más extraña que nunca por escriptura ni por memoria de gente en ningún caso hallar se pudo. Sabed que a la diestra mano de las Indias hubo una isla llamada California, muy llegada a la parte del Paraíso Terrenal, la cual fue poblada por mugeres negras, sin que algún varón entre ellas hubiese, que casi como las Amazonas era su estilo de vivir. Estas eran de valientes cuerpos y esforzados y ardientes corazones y de grandes fuerzas; la ínsula en sí, la más fuerte de riscos y bravas peñas que en el mundo se hallaba; las sus armas eran todas de oro, y también las guarniciones de las bestias fieras, en que, después de las haber amansado, cabalgaban; que en toda la isla no había otro metal alguno...» $Y$ añade: «Reinaba en aquella isla California una reina muy grande de cuerpo, muy hermosa para entre ellas, en floreciente edad, deseosa en su pensamiento de acabar grandes cosas, valiente en esfuerzo y ardid de su bravo corazón....» ${ }^{77}$.

Hernán Cortés, en unas Instrucciones dadas a Francisco Cortés, su primo y lugarteniente en la villa de Colima, ordenaba (1524) la exploración de esas costas del Pacífico: "Item, porque soy informado que [en] la costa abaxo que confina con dicha Villa [Colima] hay muchas provincias pobladas de gente donde se cree que hay muchas riquezas: e que en estas partes ay una que está poblada de mugeres sin ningún hombre, las cuales diz que tienen en la generación aquella manera que en las historias antiguas describen que tenían las Amazonas; e porque de saberse la verdad desto e de lo demás que hay en la dicha costa, Dios Nuestro Señor e Sus Magestades serán muy bien servidos, etc.) ${ }^{78}$.

Otro autor que se ocupa del tema es Gonzalo Fernández de Oviedo, en su Historia general y natural de las Indias, concluida en 1549. Por estas

76 Ibidem. Vid. J. Torre Revello, Pedro Mártir de Angleria y su obra "De Orbe Novo", Bogotá, Instituto Caro y Cuervo, 1958.

${ }_{77}$ Las Sergas de Esplandián, Madrid, 1857, págs. 539-b y 540-a ("Biblioteca de Autores Españoles), XL).

${ }_{78}^{7}$ H. Cortés, Cartas y documentos. Introd. de M. Hernández Sánchez-Barba. México, Porrúa, 1963, págs. 368-369. «Esta desorientación —escribe F. Esteve Barba, refiriéndose a los conquistadores-, este no saber dónde están —el nombre de las Indias dado al Continente es la primera de sus consecuencias-, les induce a recurrir a los mitos clásicos: los bosques se pueblan de amazonas y no falta quien haya visto sirenas en los mares. Toda la Edad Media está tras ellos, con su fantasía; y, por su parte, los geógrafos y naturalistas antiguos contribuyen en pleno Renacimiento a llenar el mundo de seres extraños) (v. Historiografia indiana, Madrid, 1964, pág. 16). 
páginas desfilan la reina Orocomay, amiga de los cristianos: Cihuatlán o Puebla de las Mujeres, en la Nueva Galicia (costa O. de México), bien dispuesta asimismo hacia los españoles; la provincia «que cae sobre el Río Grande de Santa Marta [el Magdalena]», y la expedición de Orellana, según fray Gaspar de Carvaja ${ }^{79}$.

Cuando fracasaron los intentos de localizarlas al Norte del Hemisferio, se las buscó, en efecto, al Sur. La épica marcha del Licenciado Jiménez de Quesada, desde Santa Marta a la Sabana de Bogotá (1535-1536), dio vagas noticias sobre ellas.Pero el objetivo era El Dorado, no las Amazonas. Sin embargo, Juan de San Martín y Alonso de Lebrija, en su Relación del Descubrimiento y conquista del Nuevo Reino de Granada (1536-1539), dicen lo siguiente: "Estando el real en este valle de Bogotá tuvimos nueva de una nación de mujeres que viven por sí, sin vivir indios entre ellas, por lo cual las llamamos Amazonas, y que de ciertos esclavos que compran se empreñan, y si paren hombres los envían a sus padres, y si son mujeres, críanlas... Visto por el Teniente tal novedad en tierra como ésta, enbió a su hermano con alguna gente de pie y de cavallo a que viese si era así lo que los indios nos decían: no pudo llegar a ellas por las muchas sierras de montaña que avía en el camino, aunque allegó a tres o cuatro jornadas dellas, teniendo siempre noticia que las avía, e que eran muy ricas en oro... ${ }^{80}$.

Ahora bien, el testimonio clásico lo ofrece fray Gaspar de Carvajal, el dominico que acompañó a Orellana en la tan accidentada navegación del Amazonas, hasta su desembocadura (1541-1542). Fernández de Oviedo transcribe completa la Relación del buen fraile, que perdió un ojo durante sus peripecias fluviales. He aquí lo acontecido el 22 de junio de 1542: «Han de saber que ellos [los indios] son subjectos y tributarios a las amazonas, y sabida nuestra venida, vanles a pedir socorro, y vinieron hasta diez o doce, que éstas vimos nosotros, que andaban peleando delante de todos los indios, como capitanas... Estas mujeres son muy blancas y altas, y tienen muy largo el cabello y entrenzado, y revuelto a la cabeza, y son muy membrudas y andan desnudas en cueros, tapadas sus vergüenzas, con sus arcos y flechas en las manos, haciendo tanta guerra como diez indios.... ${ }^{81}$.

79 Vid. la ed. de la Historia natural y general de las Indias, a cargo de J. Pérez de Tudela y Bueso, 5 vols., Madrid, 1955 (vols. CXVII-CXXI de la "Biblioteca de Autores Españoles». C. Alonso del Real glosa todos los pasajes de interés sobre las Amazonas, en el cap. XI, dedicado a Oviedo (págs. 157-171).

${ }^{80}$ Cit. por I. A. Leonard, Books of the Brave, págs. 57 y 346, n. 5; ed. espñ., págs. 61-62. Vid. también: D. Ramos, El mito de Eldorado: su génesis y proceso, Caracas, 1973.

${ }^{81}$ Fr. G. de Carvajal, O.P., Relación del nuevo descubrimiento del famoso Rio Grande de las Amazonas. Ed., introd. y notas de J. Hernández Millares. México, Fondo de Cultura Económica, 1955. Oviedo transcribe integra esa relación: v. el volumen $\mathrm{V}$ de la Historia..., ed. Pérez de Tudela, págs. 373-404 y, para el comentario que hace el cronista, págs. 241-242. Vid. también, para el pasaje de Carvajal citado, I. A. Leonard, Books of the Brave, pág. 59; ed. espĩ., pág. 63. 
Así, la literatura del siglo XvI corrobora, en parte, los resultados a que la etnologia de América ha llegado en el XX, sobre las sociedades matriarcales. C. Alonso del Real fija el estado de la cuestión en una jugosa página: «Fenómenos de verdadero y propio amazonismo se dan sólo en el área caribe-arahuaca, donde se mezclan rasgos matriarcales y andriarcales con ondas expansivas de la alta cultura peruana. Una ginecocracia guerrera casi amazónica se da en Urabá, donde se mezclan elementos neolíticos con ondas expansivas de las culturas medias de la actual Colombia y del Istmo, y más remotas de las altas culturas mesoamericana o incaica. Lo demás, o son formas atenuadas de algo de lo anterior (así la simpática figura de Orocomay), o son matrilineado y matrimonio de visita, pero nada guerrero, como en Ciguatlán. Está bien puesto el nombre de río de las Amazonas....182

\section{Teratología}

Junto con las Amazonas, otros señuelos y fábulas —-de raigambre clásica o medieval, transmitidos por los autores paganos y cristianos en sus versiones eruditas o folclóricas- actuaron sobre el espíritu emprendedor de marinos, eclesiásticos y conquistadores desde el alba misma del Descubrimiento. Son tan numerosos los textos en que aparece, con toda su febril temática y fantasia, una variopinta multitud de seres extraños o irreales, monstruosos, descritos e interpretados como símbolos y alegorías por los moralistas, los teólogos y los poetas (aunque muchas veces, también, aceptados como indiscutibles por unos y otros), que me limitaré a una selección de los más representativos de tal geografia teratológica, señalando al mismo tiempo las fuentes en que los escritores de Indias bebieron ${ }^{83}$.

${ }^{82}$ C. Alonso del Real, $o b$. cit., (v. n. 74), págs. 194-195. Además de I. A. Leonard (v. n. 74), que se ocupó de las Amazonas en un sugestivo estudio (base de los capítulos IV y V de Books of the Brave): Conquerors and Amazons in Mexico, "Hispanic-American Historical Review», XXIV (1944), es importante L. Weckmann, La herencia medieval de México, 2 vols., México, El Colegio de México, 1984; v. el vol. I, págs. 73-82, con muy copiosas referencias a las fuentes primarias y secundarias. Esta obra constituye, no sólo una exposición detalladísima del legado medieval a la Nueva España (1517-1650), sino también una guía para el conocimiento de tan rica tradición en el resto de la América Hispana (v. el vol. II, págs. 737-815).

${ }^{83}$ Remito, para todas estas cuestiones, al documentado libro de C. KAPPLER, Monstruos y maravillas a fines de la Edad Media trad. espñ., Madrid, Akal, 1986. Deberán tenerse presentes asimismo las observaciones de J. LE GoFF en Lo maravilloso y lo cotidiano en el Occidente medieval, trad. espñ., Madrid, Gedisa, 1985, pág. 9-24.

Sobre Colón y su credulidad, v., p. ej., A. Ballesteros y Beretta, Cristóbal Colón y el Descubrimiento de América, Barcelona, Salvat, 1945, pág. 22; y C. Pereyra, La conquista de las rutas oceánicas, Buenos Aires, Virtus (s.d.), pág. 53. L. Weckmann, ob. cit., vol. I, págs. $71-$ 100 , pone a contribución las fuentes y bibliografia sobre la geografia teratológica. Vid. también 
Entre los autores antiguos, cuyas descripciones y noticias al respecto ejercieron gran influencia durante los siglos medios y en la época de los grandes viajes oceánicos, se hallan Ctesias de Cnido, Plinio el Viejo, Gayo Julio Solino, San Agustín y, en el período de síntesis germanolatina, San Isidoro de Sevilla. Textos muy utilizados fueron asimismo el Physiologus y los bestiarios, sin olvidar, claro está, los libros de Marco Polo y del supuesto médico Jehan de Mandeville, a los que se añadirán, del siglo Xv, la Imago Mundi del cardenal Pierre d'Ailly y las Crónicas de Hartmann Schedel.

Ctesias ( $f l$. ca. 415-398 a. de J.C.), médico griego al servicio de Artajerjes II, recogió en sus Persiká e Indiká muchos datos reales o legendarios sobre aquellos países, que desgraciadamente se han perdido, salvo algunos libros y extractos debidos a Focio, patriarca de Alejandría, en el siglo IX. Conociéronle, a su vez, Eusebio de Cesarea (siglo Iv) y los sucesivos historiadores eclesiásticos, por lo que el eco de Ctesias (al que ya en la Antigüedad Estrabón, Plutarco, etc., descalificaron como geógrafo e historiador, a causa, según ellos, de su absoluta falta de sentido crítico) llegó hasta la Baja Edad Media ${ }^{84}$.

El consultadísimo erudito romano Plinio el Viejo (23/24-79 de J.C.), suministró copioso material antropológico en el libro VII de su Historia Natural y, sobre los animales, en los libros VIII-XI. Es patente la huella de este autor a lo largo del Medioevo y del Renacimiento ${ }^{85}$.

En cuanto a Solino (mediados del siglo III de J.C.), fue también muy leído y citado como Polyhistor: su obra carece de originalidad, pues consiste en un inventario de prodigios y fábulas tomados — sin nombrarle- de Pli-

las obras de N. L. Goodrich, A. Graf y L. Olschki, citadas en la n. 73, a las que se añadirán para América: G. Chinard, L'éxotisme américain dans la littérature francaise au Xvie siècle. Paris, Hachette, 1911, y A. Gerbi, La naturaleza de las Indias Nuevas: de Cristóbal Colón a Gonzalo Fernández de Oviedo, trad. espñ., México, Fondo de Cultura Económica, 1978. Los antecedentes clásicos y medievales, con abundantes referencias, se verán (aparte de los autores consignados en la n. 73) en : R. Bernheimer, Wild Men in the Middle Ages. Cambridge, Mass., Harvard University Press, 1952. J. Baltrusaitis, Le Moyen Age fantastique, Paris, 1955. F. Klingender, Animals in the Art and Thought to the End of the Middle Ages, Londres, Routledge and Kegan Paul, 1971. E. Mâle, L'art religieux en France au XIT siècle, Paris, 1966, y L'art religieux du xille siècle en France, $9^{c}$ éd., Paris, 1958. H. Mode, Fabulous Beasts and Demons. Engl. transl. Londres, Phaidon Press, 1975. L. Olschki, Marco Polo's Asia, Engl. transl., Berkeley, Cal., University of California Press, 1960. S. Sebastián, Mensaje del arte medieval. Córdoba, Ediciones El Almendro, 1984, págs. 33-35, 104-105 y 141-144.

${ }_{84}$ Cf. A. Lesky, Historia de la literatura griega, trad. espñ., Madrid, Gredos, 1976, págs. 653-654. Remite a F. Jacoby, ed. F. Gr. Hist. 688: Die Fragmente der Griechischen Historiker. 3 vols., Berlin-Leiden, Brill, 1923-1943 (repr. 1962).

${ }^{8}$ Todavía es aprovechable - pese a sus insuficiencias críticas, dada la fecha - la traducción de M.E. Littré: Histoire Naturelle de Pline, 2 vols., Paris, 1860. Para las nuevas ediciones, v. P. Grimal, Guida allo studio della civiltà latina, trad. ital., Milán, U. Mursia, 1975, págs. 144145 y 173. Sobre su fortuna hasta el siglo XVI, v. R. R. Bolgar, The Classical Heritage and Its Beneficiaries: from the Carolingian Age to the End of the Renaissance, New York, Harper and Row, 1964, págs. $105,163,169,232,263,276,328,415,423,428$ y $532-533$. 
nio el Viejo, aunque se basa en otros escritores romanos, como Suetonio (Prata) y Pomponio Mela. Sus Collectanea rerum memorabilium, suma geográfica del mundo entonces conocido, gozó asimismo de amplia credibilidad en el Occidente medieval ${ }^{86}$.

A Solino y Plinio tuvo presentes San Agustín, en La Ciudad de Dios (lib. XVI, cap. III, 1-2), cuando se refiere a ciertas clases de hombres monstruosos y, por extensión, se plantea la existencia de pueblos con tales características. Menciona, v. gr., a los cíclopes, esciápodos (que se hacen sombra en países cálidos con su único y enorme pie), cinocéfalos (hombres con cabeza de perro), andróginos, etc. «De todos modos - arguye-, no es preciso creer en la existencia de todas esas clases que se dice de hombres. Sin embargo, cualquiera que nazca como hombre, esto es, un animal racional mortal, por extraña que pueda aparecer a nuestros sentidos la forma de su cuerpo, su color, movimiento, voz, o dotado de cualquier fuerza, parte o cualidad de la naturaleza, ningún fiel podrá dudar que trae su origen del único primer hombre». Y agrega: «La explicación que entre nosotros se da de los partos monstruosos de los hombres, puede valer igualmente para explicar la monstruosidad de algunos pueblos. Dios, que es el creador de todas las cosas, conoce dónde y cuándo conviene o ha convenido crear algo, sabiendo de qué semejanza o de semejanza de partes ha de formar la hermosura del universo. En cambio, quien no alcanza a verlo todo en conjunto, se siente contrariado por lo que cree deformidad de alguna parte, ya que ignora su adaptación o referencia». Concluyendo: «Pero, si son hombres aquellos de quienes se han escrito esas extrañas propiedades, ¿por qué Dios no pudo crear algunos pueblos asi? Evitaría de ese modo nuestra posible creencia de que en tales monstruos, nacidos entre nosotros evidentemente del hombre, se habia equivocado su sabiduría, autora de la naturaleza humana, como le ocurre a un artista de poca pericia. Por consiguiente, no debe parecernos absurdo que, así como hay en algunas razas hombres-monstruos, así pueda haber en todo el género humano pueblos-monstruos»" ${ }^{87}$.

Una fuente común a los autores cristianos desde fines del siglo IV, aproximadamente —cuando se la tradujo al latín-, fue la colección griega de anécdotas, ya históricas, ya —en su mayoria - del reino animal, simbólicas y moralizantes, conocida bajo el título de Physiologus («El naturalista»), que obtuvo gran éxito en la Edad Media latina y del Cercano Oriente. Casi todos los bestiarios acusan su influencia. Constituye, además, una expresiva muestra de la pérdida del nervio en el plano cientifico, a partir de Teofrasto, con el surgimiento de una literatura de «maravillas» popular, edificante y

${ }^{8}$ Hay una trad. espñ., por Cristóbal de las Casas: De las cosas maravillosas del mundo, Sevilla, 1523, y una ed. critica de Th. Mommsen, 2." ed., Berlín, 1895.

${ }^{87}$ Cf. La Ciudad de Dios, trad. espñ., 2 vols., 3." ed., Madrid, Editorial Católica Española, 1978 (B.A.C., vols. XVI-XVII de las Obras); v. vol. II, págs. 245-249. 
dominada por la Biblia. Se remonta, al parecer, en su materia y primera composición al siglo il a. de J.C., concretamente al Egipto de Bolo de Mendes ${ }^{88}$.

Así como San Agustín se ocupó de los monstruos en el libro citado, siguiendo a Plinio el Viejo y otros textos, así también San Isidoro de Sevilla (560/570-636) les concede atención en las Etimologias (lib. XI, cap. III), donde enumera los más notables portentos, ostentos («como manifestando algo futuro»), monstruos y prodigios, distinguiendo entre unos y otros. Desfilan, por ejemplo, los andróginos, gigantes, cinocéfalos, cíclopes, blemmyas (nacidos en Libia, sin cabeza, con los ojos y la boca en el pecho), panotios, sátiros, esciápodos, hipopodas (de la Escitia, con forma humana y pies de caballo), macrobios (en la India, "que tienen ocho pies de estatura»), Gorgonas, sirenas, Hidra, Quimera, centauros, Minotauro, etc. Estos pasajes isidorianos ejercieron profunda influencia en la imaginación medieval: el libro XI, «breve antropología natural —dice S. Montero Díaz-, tal como la ciencia del hombre anterior al siglo vil podía sugerírsela..., concluye con una breve teratología más mítica que natural... Isidoro describe los tipos de prodigio que la antigüedad había forjado con objetividad, sin prestar personalmente crédito a la existencia de cíclopes y sátiros ${ }^{89}$.

El ilustre historiador del arte medieval francés, y autoridad en iconografia, E. Mâle, ha puesto de relieve asimismo entre las fuentes de inspiración alegórico-simbólica, para la escultura románica, la Imago Mundi de Honorio de Autun (comienzos del siglo XII), probablemente un alemán relacionado con los medios monásticos de Inglaterra, y que acaso transmitió motivos e ideas al maestro de Vézelay. Otro autor muy leído fue Vicente de Beauvais (¿1190-1264?), cuya enciclopedia Speculum Maius (en sus cuatro partes: Naturae, Scientiae, Morale e Historiale) informó sin duda la plástica del gótico ${ }^{90}$.

Los bestiarios representan a esos seres tan raros en bellas miniaturas que, a su vez, excitaban la imaginación de los artistas, escritores y viajeros. Trátase de obras anónimas o colectivas, cuya temática se remonta a los orígenes de la Humanidad y, más tarde, al antiguo Oriente, la tradición clásica y los Padres de la Iglesia. Tienen, por igual, subido valor folclórico y literario; aunque, como advierte $T$. $H$. White, un bestiario es también «una seria obra de historia natural y una de las bases sobre las que se fundamenta nuestro conocimiento de la biología, pese a lo mucho que hayamos avan1971.

"Vid. "El fisiólogo». Bestiario medieval. Introd. y notas de N. Guglielmi, Buenos Aires,

${ }^{89}$ Cf. la trad. de las Etimologias por L. Cortés y Góngora, con Introducción general e Indices por S. Montero Díaz, Madrid, Editorial Católica Española, 1951, págs. 47 y 279-283 (B.A.C., 67). Para la tipología del monstruo, v. el capitulo IV de la obra de C. Kappler (n. 83), págs. 131-232.

${ }_{90}$ Vid. n. 83, para las observaciones de S. Sebastián. 
zado desde que se escribió" "91. El Physiologus entra generalmente en su composición, junto con los autores griegos y romanos ya mencionados, a los que pueden agregarse Heródoto y Aristóteles.

Ya en la Baja Edad Media, cuando Europa - tras las Cruzadas- se abre a los contactos religiosos y comerciales que se inician a partir de las misiones enviadas por Roma al Imperio mongol y, sobre todo, de viajes como el de Marco Polo al Lejano Oriente, los libros de «maravillas» se sucederían reavivando tan pintoresca temática. Il Milione (1298) del audaz y curioso mercader veneciano difundiría, en efeoto, multitud de relatos y descripciones que, como es sabido, estimularon poderosamente la exploración terrestre y marítima en los siglos XIV y XV. Colón llevó consigo, al emprender su primer viaje, un ejemplar de la obra que le hizo soñar con Asia navegando hacia el Poniente. A ella debe añadirse la Imago Mundi, del cardenal Pierre d'Ailly (Petrus de Alliaco, $f l . c a .1400)^{92}$.

A mediados del siglo XIV vio la luz otro singular monumento imaginativo, el Libro de las maravillas del mundo atribuido a Juan de Mandeville - acaso un médico de Lieja-, que cautivó a los lectores de los siglos XV al XVII. En rigor, lo forman un viaje a Tierra Santa y una 'vuelta al mundo' por la India, el archipiélago malayo y China. También Colón gustaría de esta obra, en la cual se combinan las noticias veraces con los relatos fabulosos o legendarios. Traducida al castellano y editada en Valencia (1521, 1524 y 1540), contiene grabados en madera o xilografias del Liber Chronicarum, de Hartmann Schedel (Nuremberg, 1493), debidos a Wohlgemuth, suegro y maestro de Durero, con representaciones de monstruos según las fuentes clásicas y medievales arriba indicadas. Reaparecen, asi, las criaturas del elenco isidoriano, más las consignadas por Ctesias y Plinio. De los cinocéfalos dice que existian unos 120.000 (v. lib. II, cap. 51), localizándolos en la isla circular de Bacemerán y presentándolos de este modo: «... tienen cabezas de perros y los llaman canefalles, e son razonables e de buen entendimiento, y adoran a un buey... Y van todos desnudos, salvo que llevan un poco de trapo con que cubren sus vergüenzas. Aquestas gentes son grandes de cuerpo y fuertes combatientes. E llevan una adarga al cuello con que se cubren el cuerpo, y una lanza en la mano; y si toman algún hombre en la batalla, ellos se lo comen. Y en esto parecen bien canes». A los cíclopes

${ }^{9}$ The Bestiary: a Book of Beasts. Being a Translation from a Latin Bestiary of the Twelfth Century, made and edited by T. H. White, New York, G. P. Putnam's Sons, 1960, pág. 231. Vid. también la n. 83, junto con el interesante librito de J. L. Borges, Mamual de zoologia fantástica, México, Fondo de Cultura Económica, 1971 (Colec. Breviarios, 125). Add.: Bestiaires du Moyen Âge, éd. G. Bianciotto, Paris, 1980, y Bestiario medieval. Edición a cargo de I. Malaxecheverría, Madrid, Siruela, 1986.

${ }_{92}$ Es importante L. Olschki, Marco Polo's Asia, Engl. transl., Berkeley, Cal., University of California Press, 1960. Para el cardenal Pierre d'Ailly, v. G. Chinard, L'éxotisme américain... (cit. en la n. 83), pág. 25, n. 1 . 
los sitúa en una isla de la India, "como gigantes, y no tienen sino un ojo en medio de la frente, los cuales no comen sino carne y pescado sin pan" (lib. II, cap. 53). Se extiende sobre los gigantes en el capítulo 67: «algunos dellos - afirma - tienen treinta y cinco o cuarenta pies en largo, y andan todos desnudos, solamente que se cubren con pieles de bestias salvajes; e no tienen casas ni comen pan, sino carne y pescado crudo, y comen de mejor grado carne de hombres que otra cosa alguna... Entonces me decían los marineros que en otra isla más adelante había de mayores gentes de cincuenta y cinco fasta sesenta pies, los cuales por cierto yo no los he visto", Menciona asimismo a los blemmyas, acéfalos y con los ojos y boca en el pecho: tema iconográfico que se ha documentado en las catedrales de $\mathrm{Fe}$ rrara y Toledo, cuya sillería gótica, por el maestro Rodrigo Alemán, parece inspirada en los grabados de Schedel, al igual que los panocios u hombres orejones, los esciápodos (muy frecuentes en los capiteles románicos), etc. Habla igualmente de los pigmeos y de los hombres-grullas, que «tienen el cuello tan largo como una grulla, y la frente y los ojos como hombre, y el rostro agudo como de un perro y de una grulla» (lib. II, cap. 55) ${ }^{93}$.

Los textos relacionados hasta aquí, antiguos y medievales, dejaron su profunda huella en la mentalidad y escritos de los descubridores y de quienes, en el Viejo o en el Nuevo Mundo, trataron de asuntos indianos. Tan sólo para la Nueva España, L. Weckmann ha reunido copiosos testimonios y datos - geográficos, literarios, artísticos, historiográficos, etc.- que prueban esa pervivencia secular de mitos, leyendas y consejas desde el Río Grande y California hasta la Patagonia ${ }^{94}$.

La creencia en los gigantes, alimentada por la mitología clásica y por el hecho de morar en determinados países hombres de gran talla, condujo a su ubicación cartográfica mucho antes de los Descubrimientos geográficos: la isla de Taprobana (Ceilán o Lanka) era, por ejemplo, uno de esos países. En lo que respecta a la Nueva España, los restos de animales fósiles (mastodontes, Equus primigenius, etc.) también inducían a admitir la existencia de seres humanos, ya remotos, ya actuales, considerados gigantes. Tanto Américo Vespucci como Pedro Mártir de Anghiera o Angleria, Antonio Pigafetta, Bernal Diaz del Castillo, el propio virrey Mendoza, el P. Las Casas, fray Bernardino de Sahagún, el piloto Alonso Alvarez de Pineda (al

\footnotetext{
${ }_{93} V i d$ la ed. facsimil, con prólogo de J. E. Martinez Ferrando, del Libro de las maravillas del mundo, según la ed. valenciana de 1524 (2 vols., Madrid, Col. Joyas Bibliográficas, 19581960).

${ }^{94}$ Remito a las páginas 71-100 de la obra de L. Weckmann (v. n. 82), con todos los pasajes relativos a esta teratología en Indias.
} 
servicio de Ponce de León), el Inca Garcilaso, etc., hablan de ellos y, en ocasiones, de su contrapartida, los pigmeos ${ }^{95}$.

En lo que atañe a la multiforme variedad de monstruos, las islas del Caribe y el Continente americano exaltaban asimismo la fértil imaginación de los españoles: Colón, Las Casas, Pedro Mártir, Fernández de Oviedo, etc., mencionan sirenas y tritones, conforme a la tradición antigua y medieval (Alonso de Madrigal, «el Tostado», dedica a las sirenas 18 capítulos en sus Comentarios a Eusebio); los cinocéfalos u hombres husmeadores no ofrecían dudas a Colón, Diego Velázquez en sus Instrucciones a Cortés, Fernández de Enciso...; por su parte, los esciápodos y hombres con cola preocupaban al Almirante y a Pedro Mártir; los blemmyas o estetocéfalos vivían, según Sir Walter Raleigh, a orillas del río Caura, un afluente del Orinoco. Y, en cuanto a los orejones o panotios de Ctesias, Juan de Grijalva prestó oídos al testimonio de un indio maya, según el cual habitaban frente a las costas del Yucatán; mientras que fray Pedro Simón los sitúa en California y con unas orejas tan generosas que podría, si quisiera, resguardarse debajo de ellas media docena de españoles intrépidos...

Otros seres fabulosos recorren las páginas de los escritores de Indias: el águila bicéfala, milenario símbolo heráldico, fue objeto de atención hasta fines del siglo XVIII, por lo menos en la Nueva España; el dragón y el cocodrilo (o la cocatrix, con alas y patas de gallo y cola de serpiente), figuran en Las Casas y Oviedo, quien se refiere a ellos como causantes -entre otros factores- de la despoblación de las Antillas; la sierpe (¿iguana?) que tanto impresionó a Colón y a Las Casas, con su "cerro de espinas grandes desde las narices hasta lo último de la cola", animal que, por sus aletas, se relaciona con el mito de Quetzalcóatl y con la cristianización del territorio de Puebla; la hidra, el basilisco, la salamandra, el pegaso y, como creación por excelencia del folclor antiguo y medieval, el unicornio, aparecen en los relatos de Nicolás Federmann, Baltasar de Obregón, Dávila Padilla, fray Marcos de Niza, el explorador Frobisher, León Pinelo, etc., ya en la Nueva España, ya en la Florida o en las praderas de Nuevo México; por último, los grifos, mitad leones y mitad águilas, vuelan por doquiera en California, México, Venezuela, Río de la Plata...

Entre esos animales fantásticos, el unicornio se destaca por su bella leyenda, que Richard de Fournival evoca en su Bestiario de amor, a mediados del siglo XIII: «... su naturaleza es tal que ningún otro animal es tan dificil y peligroso de capturar; y tiene en mitad de la frente un cuerno al que ninguna armadura puede resistir, por lo que nadie se atreve a atacarle ni a

${ }^{95}$ Cf., p. ej., el testimonio de A. Pigafetta, Primer viaje en torno del Globo, con notas de C. Amoretti, trad. espĩ., Buenos Aires, Espasa-Calpe Argentina, ${ }^{2} 1943$, págs. 56-62, acerca de los patagones (Colec. Austral, 207). 
intentar verle, como no se trate de una joven virgen. Pues cuando su olfato le descubre una, corre a arrodillarse ante ella y saluda humildemente y con dulzura, como si se pusiera a su servicio. De forma que los cazadores avispados, conociendo su naturaleza, colocan una joven virgen en su camino, y el Unicornio viene a dormir en su regazo. Entonces, una vez que se ha dormido, aparecen los cazadores que no osaron atacarle cuando estaba despierto, y le matan ${ }^{96}$.

Así, pues, simbólicamente el unicornio representa esa continuidad de lo fabuloso antiguo, según Ctesias, Plinio el Viejo, el Physiologus Graecus, San Isidoro de Sevilla y los bestiarios, manifiesta en el Descubrimiento, la Conquista y la Colonización de América como empresas que aunaron las tradiciones clásica y medieval, tan ostensibles en los diversos ámbitos culturales hasta la Ilustración.

* R. de Fournival, Bestiario de amor, trad. espñ., Madrid, Miraguano, 1980, págs. 49-50 (Colec. «Libros de los malos tiempos", 4). Vid. asimismo J. L. Borges (ob. cit. en la n. 91), págs. 144-146. 